\title{
Sufficiency Economy Philosophy for Sustainable Food
}

\author{
Kannikar Khaw-ngern ${ }^{1}$, Nattakitt Udomphol ${ }^{2}$, Lampong Klomkul ${ }^{3}$, Chainarong Khaw-ngern ${ }^{4}$ \\ ${ }^{1,2}$ Faculty of Buddhism, Mahachulalongkornrajavidyalaya University, \\ ${ }^{3}$ Faculty of Education, Mahachulalongkornrajavidyalaya University, \\ ${ }^{4}$ Faculty of Humanities, Mahachulalongkornrajavidyalaya University \\ ${ }^{1}$ kannikar.khaw@gmail.com, ${ }^{2}$ nattakittu@gmail.com, ${ }^{3}$ research.mcu@gmail.com, ${ }^{4}$ chainarong.kha@mcu.ac.th
}

\begin{abstract}
Ending hunger, achieving food security, and promoting sustainable agriculture are the goals to be achieved by 2030 according to Sustainable Development Agenda. It aims to achieve the goals through increasing the agricultural productivity and incomes of small-scale food producers which include indigenous peoples, family farmers, pastoralists and fishers. The purpose of this article is to study causes of global hunger and SDGs Goal 2 for the guidelines of ending hunger and to suggest an aligning principle of Sufficiency Economy Philosophy for solutions to hunger. Documentary study and literature review were used for data collection. It is found that Sufficiency Economy Philosophy (SEP), consistent with the SDG2 goal, has produced many best practices for the past two decades. It suggests the model of small farm management under "New Theory" based on Sufficiency Thinking. It provides guidelines for farmers to divide their plots into four sections under the 30:30:30:10 formula for integrated farming. This basic model can be modified to suit different geographical conditions and farm sizes, but it requires farmers to live their life with moderation, respect for, recognition of local knowledge and local management of natural resources. It can be a means to improve the quality of life in rural areas, ensure enough food for present and future generations, and generate sufficient income for farmers. Apart from gaining year-round food security from integrated farming, farmers eventually become debt-free and end hunger.
\end{abstract}

Keywords

Sufficiency Economy Philosophy, The New Theory, Sustainable Food, Zero Hunger, Sustainable Development Goals: Goal 2

Article Received: 10 August 2020, Revised: 25 October 2020, Accepted: 18 November 2020

\section{Introduction}

While the global economy is slowing down and getting worse by the spread of COVID-19, the level of food insecurity and hunger have globally been increasing, which millions of children are suffering from malnutrition. In $2019,25.9 \%$ of world population, about 2 billion people, were affected by moderate or severe food insecurity, which increased from 2014 by $22.4 \%$. Those who are facing severe food insecurity, around 750 million people, tend to run out of food and, at worst, go a day, or days, without eating. it is a big challenge for every country to eliminate and achieve food security. However, eliminating hunger alone will not ensure that everyone has access to sufficient nutritious food. To alleviate the world hunger and promote food security, countries need to take immediate action to ensure trade flowing, to strengthen food supply chains and to increase agricultural production. Another cause of world hunger is the worsening situations in sub-Saharan Africa and Latin America. Along with conflict, climate shocks and the locust crisis, COVID-19 poses an additional threat to food systems, indirectly reducing purchasing power and the capacity to produce and distribute food, which affects the most vulnerable populations. In 2020, it also causes up to 132 million more people suffer from undernourishment [1]. The 2030 Agenda recognizes that we can no longer look at food, livelihoods and the management of natural resources separately. The emphasis on rural development and investment in agriculture such as crops, livestock, and fisheries can be powerful tools in eradicating poverty and hunger, and bring about sustainable development. Achieving SDG2 will need commitments, sacrifices and behaviour changes from all of people, but by working together, we can make history and become the Zero Hunger generation [2]. Likewise, the Sufficiency Economy Philosophy's central goal is to alleviate poverty and hardship. It focuses on human wellbeing rather than wealth which leads to sustainable development in long term. It also emphasizes human security, concentrates on building people's capabilities, and promote self-reliance. Additionally, the model of small farm management "New Theory" based on Sufficiency Thinking was introduced to farmers to divide their plots into four sections under the 30:30:30:10 formula with the aim to achieve food security and farm productivity.

\section{Cause Of Hunger And Solutions}

There are many causes leading to shortage of food. Even in places where food is plentiful or can be grown, challenges like disasters, conflict or poverty prevent people from accessing it. People in poverty spend the most of their income on food for their families before fulfilling other basic needs or financing long-term goals. In a case of emergency, like illness, they may have to skip their meals and spend the money they have on such emergency. And that make the cycle of hunger begins. (as figure 1) Hunger can also stem from inadequate food systems, like a lack of road infrastructure to connect people to markets, or poor storage facilities, through which food gets wasted before reaches those who need it. 


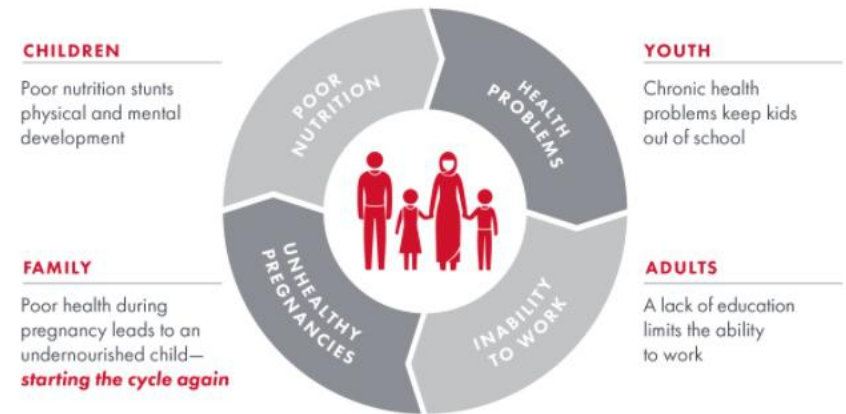

Figure 1. The cycle of hunger [3]

Hunger is the painful sensation caused by lack of food. people who get less than 1,800 calories of food per day is considered undernourished. The problem of hunger can include malnutrition, both undernutrition, meaning lack of energy and essential nutrients, and overnutrition, caused by unbalanced diets. Food insecurity concerns food availability, food access, and food utilization [4].

The most frequent cause of world hunger is climate change. Drought, floods, and heavy storms cause unexpected and sudden destruction leading to poverty and hunger as they damage farmland and agricultural area, especially small ones. Improper agricultural practices, such as over cropping and deforestation, can bring drought and damage soil quality leading to unproductive farming. War can be the most serious cause of poverty and hunger because it violates food access and food security. People will suffer from violence, lack of infrastructure, decreasing income, and even fleeing from their home [5]. According to studies, world hunger causes over a hundred million children to be underweight and one-third of children in a developing country have their growth stunted. And over nine million people, five million of which are children, die from hunger and malnutrition [6]. Million of people around the world living in poverty cannot afford food at all or cannot access to nutritious food leading to hunger or malnutrition. Simultaneously, people living in hunger and malnutrition cannot perform their job or live their life happily. Thus, poverty and hunger are interconnected and they lead to an array of problems including social, political, and health. People living in poverty and hunger normally don't have appropriate care practices and lack of access to clean and safe environment, health services, and education. Their circumstances can be worse in the case of political and social conflicts and climate changes. In countries dependent on primary-commodity export revenues, especially agricultural products and oil, there may be shortage of food supplies when the two countries have political conflicts. Drought and storms can also exacerbate food insecurity. Thus, people living in poverty will find it more difficult to access to food. Government officials and organizations fighting with hunger and poverty must take these factors into their consideration when planning and establishing their policies and operational framework in order to improve access to safe, nutritious and sufficient food for all and alleviate food insecurity and poverty. Special attention is also needed to increase the agricultural productivity and incomes of smallscale food producers, implement sustainable agricultural practices, and ensure the proper functioning of markets to ensure that no one is left behind in hunger and poverty.
The eradication of hunger and poverty are major targets of the SDGs, which were approved at the 70th Session of the United Nations (UN) General Assembly in September 2015 [7]. Eliminating hunger is a UN system-wide priority and the centrepiece of the Zero Hunger Challenge promoted by the UN Secretary General's High-Level Task Force on Global Food and Nutrition Security (HLTF). Governments in various regions have responded to the call of the UN Secretary-General and have committed to eradicating hunger and poverty. To achieve zero hunger by 2030, governments and the international community need to build on approaches that have already proved effective, which combine three important elements: [8]

1. Promote more access to basic food and other needs, and enable more diverse and healthier diets that allow hungry people to receive sufficient nutrients, vitamin, and minerals through social protection programs which will help them become healthy and be able to engage more productively in economic.

2. Increasing incomes by creating more job opportunities for the poor and hungry and promote more investments in agriculture production, infrastructure, market opportunity, knowledge generation, and information and communication technologies.

3. Ensuring sustainability by promoting the sustainability of food systems, conserving natural resources and adopting sustainable agricultural practices to ensure the food security of future.

To eliminate hunger and extreme poverty, it requires social protection measures and targeted pro-poor investment to develop productive activities. It also requires social protection programmes to support smallholder farmers and other poor households in overcoming financial constraints and in better managing risks which, in turn, strengthens their capacity to invest. To achieve the goal of zero hunger by 2030, governments must find collaboration from private enterprises, local organizations, and local people to design and build up practical strategies for effective implementation and ensure long-term access to food and provide better living conditions for the poor and hungry.

\section{SDGS: Goal 2: End Hunger, Achieve Food Security And Improved Nutrition And Promote Sustainable Agriculture}

The aim of SDG Goal 2 is to sustainably end all forms of hunger and achieve food security by 2030 . It targets all the hungry in all regions must have sufficient nutritious food to stay healthy and be able to perform their work and enjoy their living. To achieve this, governments in all regions must provide better access to nutritious food and promote sustainable agriculture. That means there must be practical plans and strategies to improve productivity and incomes of small-scale farmers through providing equal access to land, technology and markets as well as sustainable food production system and flexible agricultural practices. In developing countries, international investment must be required to enhance productive capacity.

There is some progress in hunger eradication. The number of undernourished people around the world decreased from 
$15 \%$ in $2000-2002$ to $11 \%$ in $2014-2016$. However, over 790 million people still lack of regular access to sufficient food. The areas that are facing food insecurity include sub-Sahara Africa with the percentage of undernourished people over $20 \%$ and Southern Asia with the percentage of undernourished people over 15 during 2014-2016. An estimated $26.4 \%$ of the world population, about 2 billion persons, were affected by moderate or severe food insecurity in 2018 , an increase from $23.2 \%$ in 2014 , owing mainly to increases in food insecurity in sub-Saharan Africa and Latin America. In 2019, 47 million under-5-year-old children or $6.9 \%$ were affected by wasting (low weight for one's height) or acute undernutrition, or a condition generally caused by limited nutrient intake and infection [9]. The main causes of this food insecurity come from natural and humaninduced disasters or political instability. In 2014, there was an estimate of 158.6 million children under age 5 were affected by stunning. Chronic undernutrition can put them into greater risk of common infections and lower their cognitive ability to perform well at schools. Measures to strengthen food production and distribution systems must be taken immediately to minimize the impacts of hunger [10].

Majority of poor people around the world live in rural areas. The direct and indirect sources of their income and food are from agriculture, fisheries or forestry. The main cause of hunger today does not come from lack of food because the agricultural growth in the low-income economies is getting more effective in reducing hunger and poverty. As the agricultural growth in the low-income economies is effective in reducing hunger and poverty, the hunger today is not caused by lack of supply, but because people cannot afford to buy enough food. Therefore, there must be a comprehensive action plan to fight against hunger in rural area. People living in hunger and poverty are found difficult to learn and work effectively, and they hardly can contribute to economic development, human development, environment health and innovation. Achieving the target of zero hunger of SDGs by 2030 needs collaborations from all stakeholders including central government, private enterprises, local administration, and people in the communities [11].

To ensure that poor people in rural areas can have access to nutritious food, sustainable and resilient agricultural practices and efficient agricultural production are essential. Sustainable and resilient practices for agriculture can sustainably promote enough supply while effective agricultural production provides income, employment and food at affordable prices as well as increase foreign exchange from exports. To promote a sustainable agricultural development path, practical and effective plans and strategies are required for improving the quality of life in rural areas, ensuring enough food for present and future generations as well as making sufficient income for farmers. It is necessary to maintain productive capacity and improve productivity for the future without damaging the environment. Moreover, it is necessary to recognize local knowledge and local management practices in conserving natural resources and to stimulate the capabilities of present and future generations.

Due to the constant increase of the population in the AsiaPacific region, the world population is expected to increase by 500 million by 2030 . Consequently, the food insecurity situation in various regions will become more challenging. Increasing food production to fulfill food requirement can aggravate resource extraction and damage more natural resources. To get through the challenges, many actions have to be implemented which include establishing social protection system to improve food access, make food system more efficient, diversify rural employment, adopt holistic approaches for smart and conservation agriculture, and build the resilience of rural communities [12]. (Figure 2)
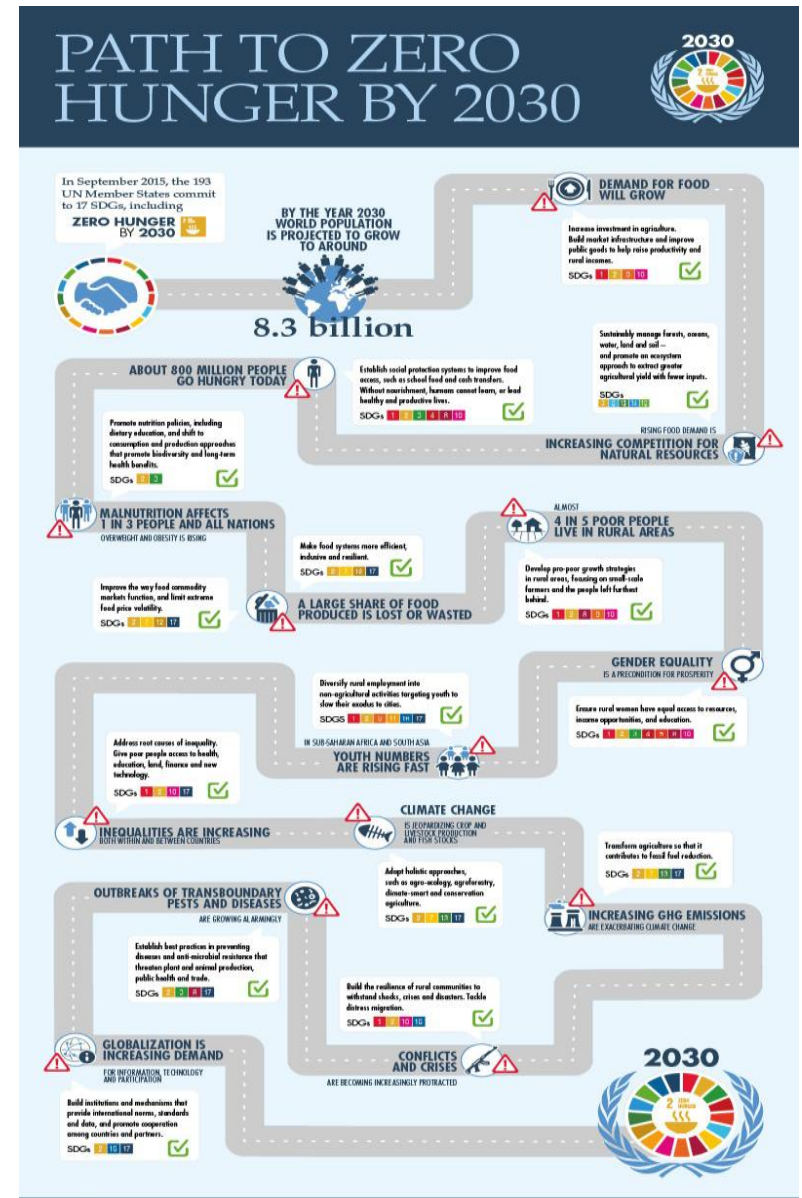

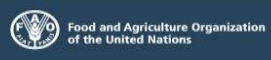

www.fao.org/3/a-i/454e.pdf

Figure 2. Trends, challenges and priority actions towards Zero Hunger [13]

Since financial crisis in 1997, Thai government started to use the SEP as a guideline for economic development program for the country. Nowadays, there are many SEP prototype villages located all over the country. It is hoped by policy makers that once the practice of SEP has been carried out by the majority of Thai people, Thailand will be able to move forward with high and sustainable economic growth, with minimal risk of failure. The Sufficiency Economy aims to enable Thailand to pursue a balanced and sustainable development of the country during the economic turndown and the coronavirus pandemic. It can lead to sustainable development of firm fundamentals of the Thai society whilst being able to adapt to any unforeseen events, whether an economic crisis, a natural disaster, or a social dilemma. Ultimately, the Sufficiency Economy practices will promote wellbeing of Thai people and sustain food security as well. 


\section{Sufficiency Economy Philosophy And The New Thoery}

The force of globalization has transformed agricultural production of the world and causes excessive agricultural export around the world. That leads to monocropping and loss of crop varieties which has damaged the environment and caused natural resource depletion and soil deterioration [14]. Excessive exports brings big amount of money to the export countries, however, it can increase the shortage of products at home. India, as an example, was the largest rice exporter in 2012, but lots of its people go hungry and live in poverty [15].

Over the course of his reign, King Bhumibol emphasised the importance of sufficiency, which aims to alleviate poverty and reducing economic vulnerability of the poor as well as to empower and strengthen the communities as foundation of the local economy [16]. The philosophy emphasizes that if everyone moderately consumes products/services and is not greedy, the people and their country will prosper. The Sufficiency Economy Philosophy aims to enable Thailand to pursue a balanced and sustainable development of the country, especially during the globalization period. It enhances the development of firm fundamentals of the Thai society and enable people to adapt to any unforeseen events, whether an economic crisis, a natural disaster, or a social dilemma. Eventually, with the practice of the Sufficiency Economy into practice, the wellbeing of Thai people will be improved [17].

Hunger used to be a critical problem for millions of people in Thailand, especially in some parts of the north and the northeast. Today, the problem is moderately found due to the economic growth during the last decades. The living standard people throughout the country has improved. According to the Food and Agriculture Organisation (FAO) of the United Nations, the numbers of Thais struggling with hunger have dropped from 19.8 million in 1990 to 5 million as of 2015 [18]. According to the extensive communitybased nutrition programmes and nationwide health campaigns targeting mothers and new-borns, the problem of malnutrition has dropped dramatically. The first Millennium Development Goal was to reduce hunger and malnutrition by half by 2015. In July, 2016, FAO honoured Thailand as among the countries which has surpassed this goal [19].

Thailand is recognized as one of the world leading riceexporters and one of the world's top exporters of seafood. The problem of hunger the country is not caused by lack of food, because of its natural abundance. Therefore, poverty and hunger normally occur when farmers stop producing food for their own consumption but focus on producing for markets which they cannot anticipate what is going to happen. Also, excessive exploitation of natural resources from industries and private sectors destroys the locals' sources of livelihoods [20]. Sufficiency Economy Philosophy recommends producing one's own food before selling the surplus to other for cash. It focuses on returning food security to farm communities over chasing for money and high risks. It emphasizes eco-friendly agriculture which will conserve environment and make people healthier. It also promotes farmers' wellbeing, both mind and body, based on moderation and contentment [21].
Through HM King Bhumibol Adulyadej's on-field research, it suggests small farm management to ensure food security and protect farmers from droughts and debts from fluctuating prices and offers the model of small farm management called "New Theory" based on Sufficiency Thinking. For short, the New Theory suggests farmers to divide their plots into four sections under the 30:30:30:10 formula. Farmers should use $30 \%$ of land for a reservoir to ensure year-long water supply for farming, another $30 \%$ for rice fields, another $30 \%$ for vegetables, field crops, fruit trees, firewood, herbs, etc., and the remaining $10 \%$ for residence and livestock areas. (Figure 3 ) The required size of land to ensure self-sufficiency should be around 10-15 rais (4-6 acres or 1.6-2.4 hectares) [22]. After achieving food security, the second stage of the New Theory advises farmers to get organised to improve their irrigation systems and farm productivity and collaborate each other for better produce, process and market their goods, preferably as cooperatives. They also should share resources to provide welfare benefits to members. Stage Three concerns the establishment of fair trade relationships between local organisations and the private sector [23].

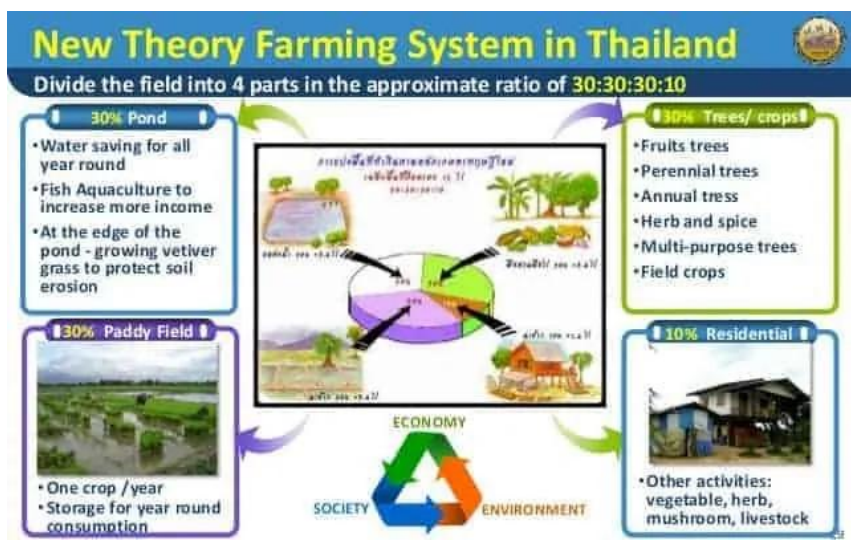

Figure 3. Layout of New Theory Farming System based on Sufficiency Economy Philosophy [24]

The New Theory is a practical model of land and water management, especially for small farms in the natural condition, both in normal times and in crisis. Farmers can define, plan, and implement the farming by themselves according to steps and procedures they have set. The New Theory aims to solve the problem of water shortages and enable farming on limited land in order that they can produce sufficient amount of food for their families and sell the surplus to the markets [25].

There are three phases for agricultural management in the New Theory.

Phase 1: Farmers put their effort to live at sufficient level by producing enough food for their families, living in a good environment, and enjoying good health, through integrated farming on their land which is divided into the three zones as described above.

Phase 2: Farmers are encouraged to organize themselves into groups or cooperatives to conduct various activities in coordination with related government agencies, foundations, and private enterprises. These activities focus on production, marketing, daily living, welfare, education and social and religious affairs. Some examples for the activities relate crop seeds and soil preparation for production, distribution 
channels for marketing, value-added products for daily living, health insurance and loans for community welfare, scholarships for education. If the community members work together in groups, they will be able to reduce their dependency on external parties, while increasing their bargaining power in the acquisition of production factors and the sale of their produce. Transportation and marketing costs can also be reduced in through economies of scale and production planning can be done for community common benefits [26].

Phase 3: Farmers should build up connections with other organizations and agencies for getting supports in capital, marketing, and energy, in order to expand commercial activities with better facilities and more channels such as the setting up of rice-mills, community shops, and service stations. They will be provided more chances to learn and have more experience in production, processing of agricultural products, marketing, and even exporting. In this way, farm families can earn more income and live happily, and the community is strengthened. Farmers will learn by doing at all steps and be able to promote sustainable development in their community.

To ensure food sustainability according to the New Theory of Sufficiency Economy Philosophy, government, both at regional and national levels, play important roles in providing guidance, support, and supervision for farmers. Those concerning market functions that can hinder development, such as asymmetric information, imperfect and missing markets, and law enforcement problems, still require government actions. Government can build strong institutions and deepen and facilitate market functions to maximize the welfare of the people under the moderation framework. Policy making should be done with deliberation and caution, and should be subjected to experience and knowledge attainment. Any policy launched should be done with careful evaluation in order to avoid a destructive impact on the economy. In this manner, the economy will be able to withstand crises and shocks from the outside world [27].

All three phases of the New Theory require support and cooperation from outside. The government can get collaboration from private and business sectors in providing some supports to farmers as following:

Educate and give assistance to small farmers who stay in the state's allocated land how to do integrated farming according to the new theory procedure.

Guide local organizations and farmers to be able to analyze and draw up their own farm production plan at community level with the technical and information support from the extension agents.

Encourage farmers' institutions or local communities to reduce the dependence upon external funds and promote rural savings as internal funds, instead. This fund can be used for improving production efficiency, supporting agro-industries towards the production of valueadded products. In addition, another fund should be set up to assist farmers and farmers' institutions for marketing aspects.

Provide services in acquiring planting materials and breeding animals at fair prices for farmers to get start.
Encourage farmers at household level to increase value of the products and develop a wide variety of product types to meet market demand.

Collaborate with farmers and local organizations in the establishment of local markets as places for purchasing and selling agricultural products in each locality.

Facilitate the setting-up of agricultural product storage at local level and encourage the utilization of the existing ones so that the products can be gradually supplied to the markets according to the periodic demand.

This basic model can be applied to different size of farm plots in different geographical conditions. When being supported by the government with cooperation from business sectors, it can be functional and effective model for food sustainability. (Figure 4)

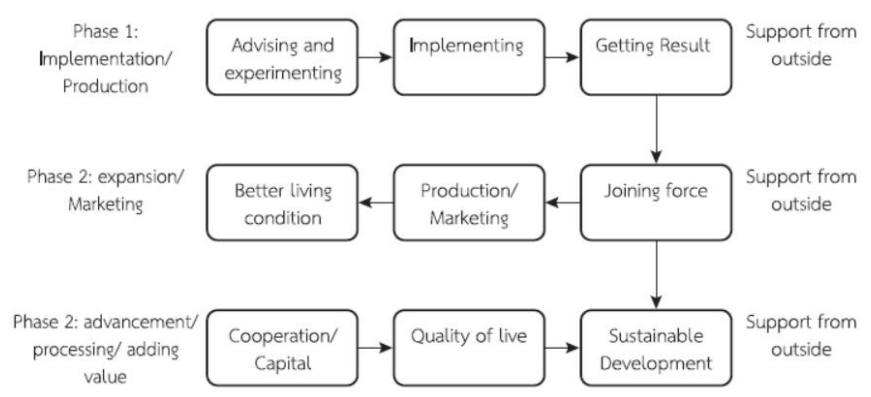

Figure 4. Procedure of New Theory Farming System in Thailand [28]

In the 1960s, monocropping approach, introduced by Green Revolution, was implemented in Thailand and it generated much more income for farmers due to increase in productivity. But disillusionment quickly set in. Toxic chemicals destroy soil fertility and farmers' health while expensive farm chemicals and uncontrollable prices force farmers into debt. Farmers have also lost food security from monocropping. This widespread problems have called for an alternative farming movement to heal the land and bring back self-reliance. The agricultural techniques employed are diverse. Some are engaging in integrated or mixed farming aiming for sufficiency. Other practices include agroforestry, natural farming, organic farming and the fallow system. Integrated and organic farming based on Sufficiency Thinking, through perseverance and care for the environment, rewards the farmers with soil fertility and food security. HM King Bhumibol Adulyadej's methodical approach to integrated farming through the "New Theory", integrated and alternative farming has become a national movement for sustainable food.

Farmers across the country have managed their plots of land as advised by the New Theory based on Sufficiency Economy Philosophy. Besides gaining year-round food security from integrated farming, farmers eventually become debt-free from selling organic produce and processed organic foods. Many farmers also open their farms as learning centres for other farmers. This agricultural procedure not only help the farm families to achieve food security, but it also promotes food sustainability at regional and national levels.

Sustainable food and zero hunger can positively impact our economies, health, education, equality and social development. It's the goal of many countries, especially in 
developing countries. It's a key piece of building a better future for us and for the next generations. Sustainable food and zero hunger can also contribute to less conflicts among people and prevent them from fleeing their homes.

\section{Conclusion}

Food is the major factor for human wellness. It nourishes human body and prevents people from hunger, so people can perform their job and enjoy they livelihood. Although food is one of the basic necessities of humans, too many people are unavoidably trapped in a cycle of hunger due to forces out of their control, like poverty, disaster, conflict and inequality. The World Health Organization considers hunger as the greatest threat to global health. It prevents people from developing their full potential to work and learn, which can curb their future and make trap them and their families in more poverty and more hunger. Hunger and poverty also can worsen the economy and hinder country development. Therefore, achieving zero hunger is one of the most urgency. A world with zero hunger can positively impact our economies, health, education, equality and social development. For years, Sufficiency Economy Philosophy has proved its benefits in alleviating hunger and improving farmers' living quality. It offers an open, participatory decision-making process whereby everyone has an equal say. People know best their problems, strengths, and constraints. SEP works different development approaches to reach sustainable development goals faster. Thailand's SEP experience is proof that the United Nations Sustainable Development Goals can indeed be attained when we truly believe that people, environmental and future generations matter. Methodical approach to integrated farming through the "New Theory", integrated and alternative farming has become movement for sustainable food. It is an efficient approach to food security, better livelihood, and better future for everyone. Government and private sectors can also play important roles in supporting, promoting, and ensuring the food sustainability.

\section{References}

[1] UN. (2020) Urgent actions are especially needed to protect the nutritional status of the most vulnerable children during the pandemic. Retrieved 19 August 2020 from https:// unstats.un.org/sdgs/report/2020/goal-02/

[2] FAO, UNICEF, WFP \& WHO. (2019). Placing Nutrition at the Centre of Social Protection. Asia and the Pacific Regional Overview of Food Security and Nutrition 2019. Bangkok: FAO.

[3] https://www.worldhunger.org/world-childhunger-facts/
[4] https://www.actionagainsthunger.org/worl d-hunger-facts-statistics

[5] Gibbs, D. (2015). Ending world hunger: Understanding causes and effects. Retrieved 19 August 2020 from https://borgenproject.org/ending-worldhunger/\#: :text=Agricultural $\% 20$ practices $\% 20$ such $\% 20$ as $\% 20$ deforestation, droughts $\% 2 \mathrm{C} \% 20$ floods $\% 20$ and $\% 20$ tropic al\%20storms.

[6] International Food Policy Research Institute. (2020). 2020 Global Food Policy Report: Building Inclusive Food Systems. Washington DC: International Food Policy Research Institute. https://doi.org/10.2499/9780896293670

[7] United Nations Country Team Thailand. (2017). United Nations Partnership Framework 2017 - 2021.

[8] [8] FAO, IFAD and WFP. (2015). Achieving Zero Hunger: the critical role of investments in social protection and agriculture. Rome: FAO.

[9] UNCT. (2019) Annual report 2018. Bangkok: UN country team Thailand.

[10] http://www.fao.org/resources/infographics/ infographics-details/en/c/1003923/

[11] https://www.greenmatters.com/p/what-ismonocropping

[12] https://www.agprofessional.com/article/co mmentary-starving-people-live-wherefood-exported

[13] http://hdr.undp.org/sites/default/files/thaila nd_2007_en.pdf

[14] Sachayansrisakul, N. (2009). Sufficiency Economy: A Reasonable Approach for Thailand's Future. NIDA Development Journal. 49 (2): 1-22.

[15] The World Bank. (2020). Thailand's Poverty on the Rise Amid Slowing Economic Growth. Retrieved 19 August 2020 from https://www.worldbank.org/en/news/pressrelease/ 2020/03/03/thailands-poverty-onthe-rise-amid-slowing-economic-growth 
[16] https://www.pressreader.com/thailand/ban gkok-post/20170526/282394104396000

[17] OECD. (2018). Multi-dimensional Review of Thailand: Volume 1. Initial assessment, OECD Development Pathways. Paris: OECD Publishing.

[18] Sripokangkul, S. \& Norkaew, Y. (2017). Lessons Learned from People Participation in Poverty Reduction based on Sufficiency Economy Philosophy, a case study of NaiMueang Sub-District, Wiang-Kao District, Khon Kaen Province. Mahachula Academic Journal. 4 (1): 107-127.

[19] Ministry of Foreign Affairs. (2017). Sufficiency Economy Philosophy: Thailand's Path towards Sustainable Development Goals. Bangkok: Ministry of Foreign Affairs.

[20] https://raktamachat.org/permaculturethailand-asia/info/rak-tamachatpermaculture-media/permaculture-masterplan/permaculture-master-plan-section-1goals-articulation/new-theory-sufficiencyeconomy/

[21] Prasopchoke Mongsawad, Asia-Pacific Development Journal Vol. 17, No. 1, June 2010 https://www.unescap.org/sites/default/files /apdj-17-1-5-Mongsawad.pdf

[22] http://www.polscilaw.buu.ac.th/journal/document/9-3/10.pdf 